\title{
Komplikasyonsuz Toraks İçi Yabancı Cisim (Mermi Çekirdeği): Olgu Sunumu
}

\author{
Foreign Body Without Complication in the Thorax (Bullet Core): Case Report
}

\author{
Ali Karakuş ${ }^{1}$, Ahmet Güngör ${ }^{2}$, Kadir Damgacı ${ }^{3}$, Hayati Kandişs ${ }^{4}$ Osman Özcan Apaydın ${ }^{3}$ \\ 'Kırıkkale Yüksek Ihtisas Hastanesi Acil Servis Kliniği, Kırıkkale, Türkiye \\ ${ }^{2}$ Kırıkkale Yüksek Ihtisas Hastanesi Göğüs Cerrahisi Servisi, Kırıkkale, Türkiye \\ ${ }^{3}$ Kırıkkale Yüksek intisas Hastanesi Ortopedi Servisi, Kırıkkale, Türkiye \\ ${ }^{4}$ Düzce Üniversitesi Tıp Fakültesi, Acil Servis Anabilim Dalı, Düzce, Türkiye
}

\section{Özet}

Toraksa yönelik ateşli silah yaralanmalarında sakatlık ve ölüm oranı yüksek olduğundan, toraks içinde kalıp herhangi bir patolojiye neden olmayan yabancı cisimlere yaklaşım konusu literatürde az rastlanır bir durumdur. Bu çalışmada, ateşli silah yaralanması sonucu acil servise getirilen, takibinde torakal komplikasyon gelişmeyen ve sonrasında toraks içindeki mermi çekirdeğiyle yaşayan bir hastanın takip ve tedavi aşamalarını incelemeyi amaçladık.

(JAEM 2011; 10: 138-40)

Anahtar kelimeler: Toraks, ateşli silah yaralanması, mermi çekirdeği

Alındığı Tarih: 30.06.2009

Kabul Tarihi: 05.08.2009

\section{Abstract}

Because of the high rates of death and severe injury due to thoracal gun shot wounds, the medical approach to bullet cores remaining in the thoracic cavity without causing any complication has only rarely been presented in the literature. In this study, we aimed to investigate the treatment and follow up stages of a patient who was admitted to the emergency department due to a thoracic gunshot wound and developed no thoracic complication.

(JAEM 2011; 10: 138-40)

Key words: Thorax, gunshot wound, bullet core

Received: 30.06.2009

Accepted: 05.08.2009

\section{Giriş}

Travma, genç erişkinlerde en sık görülen ölüm nedenidir. Göğüs travmaları, kafa ve ekstremite travmalarından sonra üçüncü sırada yer almaktadır. Göğüs travmalarında doğru tanı ve uygun cerrahi yaklaşım sakatlık ve ölüm riskinin azaltılmasının temelini oluşturur (1).

Göğüs travmalarının \%70'ini künt, \%30'unu ise penetran yaralanmalar oluşturmaktadır. Künt yaralanmaların en sık görülen nedeni motorlu tasıt kazaları, penetran yaralanmaların en sık görülen nedenleri ise ateşli silah yaralanmaları ve delici-kesici aletle olan yaralanmalardır. Penetran göğüs yaralanmalarında ölüm, künt göğüs travmalarına göre daha düşüktür. Bunun nedeni, bu yaralanmaların etkilediği alanın daha küçük olması ve eşlik eden organ yaralanmalarının daha az olmasıdır. Penetran yaralanmalar içinde ise ateşli silahlarla meydana gelen yaralanmaların ölüm oranı, diğer delici ve kesici aletlerle meydana gelen yaralanmalara göre iki kat fazladır. Günümüzde bu tip yaralanmalarda nasıl bir cerrahi tedavi yaklaşımının izleneceğinin belirlenmesi büyük önem taşımaktadır. Klinik çalışmalar, deneyimli bir ekip tarafından zamanında müdahale edilmediğinde, ateşli silahlarla meydana gelen göğüs yaralanmalarında ölüm riskinin artacağını göstermiştir.
Asemptomatik olan hastalarda metalik yabancı cisimler $2 \mathrm{~cm}$.nin üzerinde olmadığı müddetçe, bu cisimler fibröz dokuyla çevrili olduğundan çoğu otör tarafından çıkarılması önerilmemektedir. Yabancı cisimlerin lokalizasyonu ve riskleri göz önüne alınarak bir karara varılmalıdır (2-4).

\section{Olgu}

Otuz iki yaşındaki erkek hasta, otuz dakika önce ateşli silahla yaralanması nedeniyle, acil servise getirildi. Hastanın genel durumu orta, şuuru açık koopere, tansiyonu 100/70 mmHg, nabzı 110/dk, solunum 25/dk idi. Göğüs ön yüzünde sternum solunda 4-5. kot hizasında, midklavikular hatta, sol meme başı ile sternum arasında bir cm.lik etrafı düzensiz kanamalı yara(mermi giriş yeri), sol elde 2 . metakarp düzeyinde $0.5-1 \mathrm{~cm}$ 'lik etrafı düzensiz kanamalı yara( eli transvers geçen mermi giriş çıkış deliği) mevcuttu. Diğer fizik muayene bulguları normal olan hastanın sol elini kurşunlanma sırasında korunma amaçlı göğsünün üzerine koyduğu öğrenildi.

EKG' sinde normal sinüs ritmi, çekilen direkt grafilerinde sternum arkasında kalp gölgesi üzerinde 4-5. kot aralığında mermi çekirdeği (Resim 1, 2), sol elde 2.metakarp kırığı tespit edildi. Laboratuar değerleri beyaz küre 24.8-15.6 K/uL, Hb 17.2-15.6 gr/dl, Htc \%51.8-46.7, 
trombositleri 380-360 K/uL düzeyindeydi. Çekilen torakal tomografide (Resim 3) mediasten ön kısmında sternum arkasında mermi çekirdeği ve buna bağlı artefakt izlendi. Hemotoraks, pnömotoraks ve kot fraktürü saptanmayan olguya acil servi sde; yara yeri pansumanı, tetanoz aşısı, antibiyotik ve ağrı kesici tedavi uygulandı. Takip ve tedavi amaçlı göğüs cerrahisi kliniğine yatırıldı.

Göğüs cerrahisi kliniğinde tedavisi devam eden hastanın takibi sırasında herhangi bir şikayet ve komplikasyon gelişmedi. Kontrol akciğer grafilerinde herhangi bir patoloji saptanmadı. Konservatif tedavi uygulanan hastaya cerrahi tedavi gerek görülmedi. Çekilen ekokardiyografisi normal olan hasta 4.gün sonunda ayaktan takip amaçlı şifa ile taburcu edildi. Hastanın 6 aylık poliklinik takibinde bir anormallik saptanmadı.

\section{Tartışma}

Genelde ölümle sonuçlanan toraks yaralanması, toplumda sıkça görülmekte olup komplikasyon açısından acil ve sıkı monitarizasyon gerektiren bir durumdur (5). Yapılan çalışmalarda en yaygın görülen patolojilerin hemopnömotoraks, akciğer kontüzyonu ve hemotoraks olduğu, eğer göğüste büyük damar yaralanması yoksa hastanın yaşamının tehlikeye girmediği belirtilmiştir (6). Ateşli silah yaralanması olan vakalarda mermi çıkış deliği yoksa ve beklenen yerde görülemiyorsa merminin göç olasılığı düşünülmeli ve hemopnömotoraks gelişebileceği düşünülmelidir. PA akciğer ve yan dekübit grafi pleural boşluktaki cismi görmeye yarar. Bizim takip ettiğimiz hastada belirtilen komplikasyonlar gelişmemiş olup, hastanın korunma amaçlı elini göğsünün üzerine tutması sonucu azalan mermi hızının bu durumu sağladığını düşünmekteyiz.

İntratorakal asemptomatik olan bir merminin çıkarılıp çıkarılmayacağı konusu her zaman tartışmalıdır. Ateşli silahlarla meydana gelen toraks travması olgularında hemodinamik açıdan sorun yoksa rutin grafilerle ön değerlendirme yapılır. Bu değerlendirmede bir patoloji saptanmazsa olgu izleme alınır. Acil incelemeden sonraki altıncı saatte göğüs grafisi tekrarlanır. Hasta hala asemptomatik ve grafi normalse geç komplikasyon görülme olasılığı düşüktür. Bu yaklaşım toraksın delici yaralanmalarında altı saat kuralı olarak anılır (7). Çoğunlukla düşük hızlı silah ve bıçaklanma yaraları nonoperatif olarak tedavi edilebilir, genellikle sadece tüp torakostomi gerektirir. Hemodinamisi stabil iki hasta üzerinde yapılan çalışmada, pleural kavite içindeki mermi çekirdeği VATS (Video-assisted thoracoscopy) yöntemi ile çıkartılmıştır $(8,9)$. Kuru sıkı kovan patlamasına bağlı olarak akciğer kontüzyonu gelişen bir olgu üzerinde yapılan çalışmada, operasyonla mermi kovanının alınarak hasta şifa ile taburcu edildiği görülmüştür (10). Ateşli silah yaralanmalarında; merminin koterizasyon etkisi sonucu kalp,büyük damar yaralanması ve geniş göğüs duvarı defekti yoksa; kesici-delici alet yaralanmalarına nazaran operasyona daha az ihtiyaç duyulur. Transmediastinal ateşli silahla yaralanmalar son derece ölümcül olgular olduğundan bu konuda yayınlanmış çalışmalar da oldukça azdır (11). Bu çalışmada göğüs cerrahisi servisinde 4 gün takip edilen hastanın izleminde herhangi bir semptom ve komplikasyon gelişmedi. Cerrahi müdahaleye gerek duyulmayan, toraks içindeki mermi çekirdeği çıkartılmayan hasta şifa ile taburcu edildi.

Toraks içinde bırakılan yabancı cisimler sonucu nadiren enfeksiyon gibi komplikasyonlar gelişebilir. Bu nedenle büyük metal nesnelerin veya keskin kenarların temizlenmesi önerilmektedir. Literatürde travma sonrası kurşun embolisi, ventriküler ekstrasistol, tam blok,

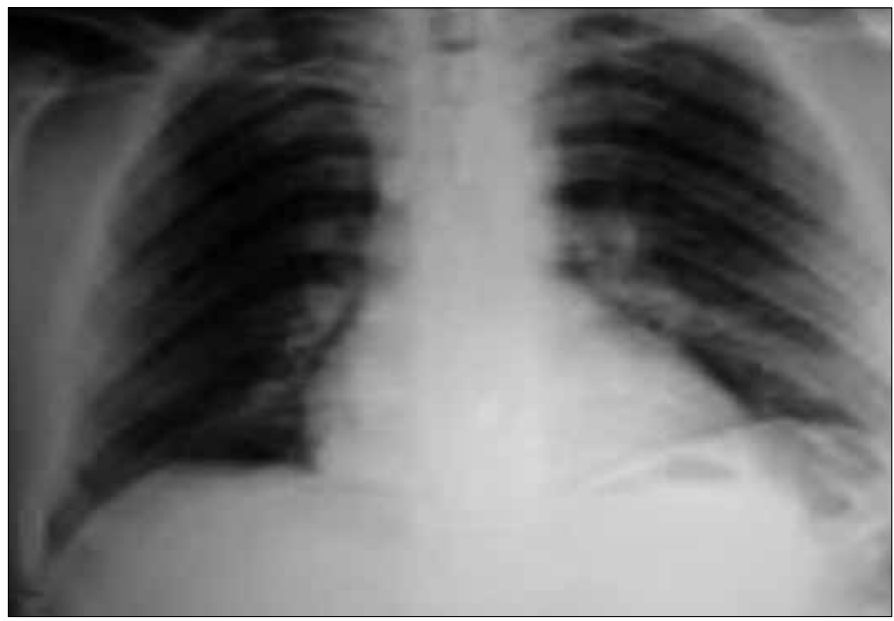

Resim 1. Sternum arkasında kalp gölgesi üzerinde mermi çekirdeği

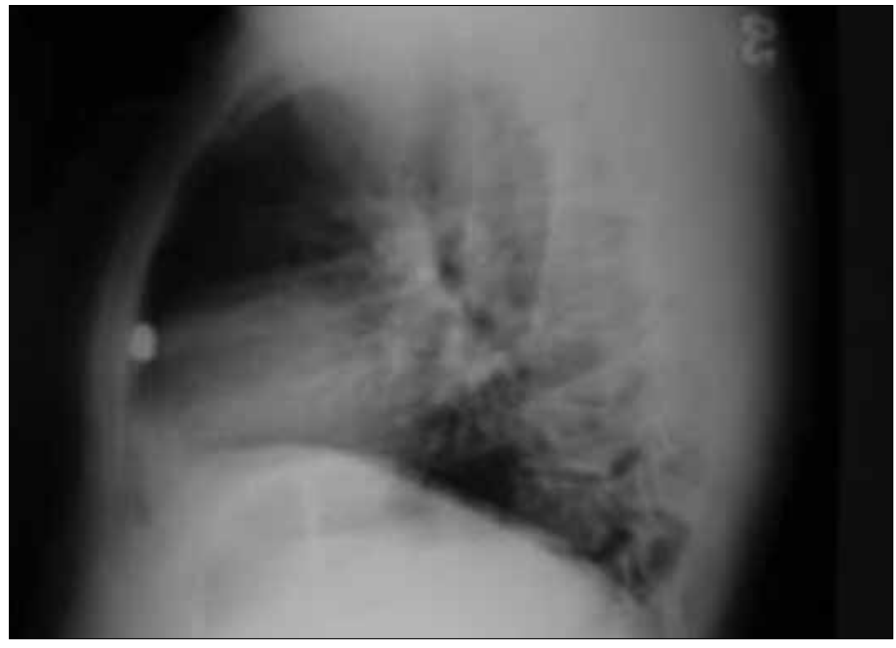

Resim 2. Toraks içi organlara zarar vermeyen mermi çekirdeği



Resim 3. Artefakt görüntüsü veren mermi çekirdeği 
koroner arter yaralanması, aort yetersizliği, tromboembolizm, kot fraktürüne bağlı hasarlanma ve subakut septik endokardit görülmesiyle ilgili yayınlar vardır. Ampiyem, hemotoraks, bronkoplevral fistül, bronşial stenoz, şilotoraks diğer gelişebilecek komplikasyonlar arasındadır (12). Bunun yanında Selinger ve arkadaşları bir çalışmalarında, ateşli silah yaralanması sonrası sol ventrikül ile sağ atrium arasında fistül gelişen bir olgunun 52 yıl asemptomatik kaldığını, konjestif kalp yetmezliği sonrası tanı konduğunu ve tedavi edildiğini bildirmektedir (13). Bizde de hastanın yapılan takip ve geç kontrollerinde herhangi bir problemle karşılaşılmadı. Çekilen direkt grafi kontrolleri, EKG ve ekokardiyografide anormallik saptanmadı, ancak oluşabilecek komplikasyonlar düşünülerek takibin devamı önerildi.

Ateşli silah yaralanmalarından sonra vücutta kalan mermi çekirdekleri yıllar sonra, çekilen ilk grafiden farklı bir morfolojide tespit edilebilir. Mermi çekirdeklerinin gelişen deformasyon ile birlikte sistemik bir zehirlenmeye de yol açması muhtemeldir. Mermi çekirdeklerinin gömleksiz yapıda olanlarında, aralıklı röntgen takiplerin yapılması veya herhangi bir nedenle gerçekleştirilecek radyolojik incelemelerde, değerlendirmeyi yapacak hekimin konu ile ilgili uyarılması gerekmektedir (14). Bunun yanında saplanıp kalan mermi veya şarapnel parçacıkları, magnetik rezonans tetkikinin yapılmasını sakıncalı kılmaktadır. Bu sakınca, ilgili metal parçacıkların yüksek manyetik alan ve güçlü radyo frekans dalgaları nedeniyle ısınması, içinde bulunduğu dokularda yanıklara sebebiyet vermeleri, küçük parçacıkların yerinden oynayarak doku zedelenmesi ve kanamalara yol açmasındandır (15). Ancak bazı hastalarda yabancı cismin vücut içinde kalması psikolojik rahatsızlıklar oluşturabileceğinden, cisimlerin vücuttan alınması için asıl önemli endikasyon bu psikolojik problem olabilmektedir (2-4). Bu yüzden gereksiz cerrahiye gidişi önlemek amacıyla olgulara psikolog desteği sağlanmalıdır. Bizim çalışmamızda takip edilen hastaya, oluşabilecek yan etkiler ve sorunlar hakkında bilgi verildi ve psikolog desteği alındı. İleri tarihlerde yapılacak kontrollerle oluşabilecek komplikasyonların takip edilmesi amaçlandı.

\section{Sonuç}

Toraksa yönelik ateşli silah yaralanması olan vakalarda ölüm ve sakatlık oranı yüksek olduğundan bu tür vakalar, hızla değerlendirilip tanı konulması gereken gruptadır. Nadir de olsa komplikasyon gelişmeyen, intratorakal ve yaşamsal organlara penetre olmamış bu tür yaralanmalarda herhangi bir cerrahi müdahaleye gerek kalmadan sağkalım gerçekleşebilmekte, toraks içindeki yabancı cismin çıkartılmasına gerek duyulmamaktadır. Ancak bu tip hastalarda belirtilen yan etkiler ve yaşam şartları anlatılarak psikolojik olarak rahatlatma sağlanmalıdır.

\section{Çıkar Çatışması}

Yazarlar herhangi bir çıkar çatışması bildirmemişlerdir.

\section{Kaynaklar}

1. Leblebici H, Kaya Y, Koçak AH. Göğüs Travmalı 302 Olgunun Analizi. Türk Göğüs Kalp Damar Cerrahisi Dergisi 2005; 13: 392-6.

2. Bartek JP, Grasch A, Hazelrigg SR. Thoracoscopic retrieval of foreign bodies after penetrating chest trauma. Ann Thorac Surg. 1997; 63: 1783-5.

3. Edil BH, Trachte AL, Knott-Craig C, Albrecht RM. Video-assisted thoracoscopic retrieval of an intrapleural foreign body after penetrating chest trauma. J Trauma 2007; 63: E5-6. [CrossRef]

4. Williams CG, Haut ER, Ouyang H, Riall TS, Makary M, Efron DT, et al. Videoassisted thoracic surgery removal of foreign bodies after penetrating chest trauma. J Am Coll Surg 2006; 202: 848-52. [CrossRef]

5. Kandiş H, Güngör A, Katırcı Y, Deniz H, Deniz T. Göğüs Travmalı Olguların Demografik Özellikleri. Türkiye Acil Tıp Dergisi 2009; 9:19-23. [CrossRef]

6. Erdik O, Karasu S, Haberal I, Büyükdoğan V, Ersöz N, Sanal H. Ateşli silahlarla meydana gelen göğüs yaralanmalarında cerrahi deneyimimiz: 258 olgunun değerlendirilmesi. Türk Göğüs Kalp Damar Cerrahisi Dergisi 2007; 15: 59-63.

7. Kerr TM, Sood R, Buckman RF, Gelman J, Grosh J. Prospective trial of the six hour rule in stab wounds of the chest. Surg Gynecol Obstet 1989; 169 : 223-5.

8. Marsico GA, Almeida AL, Azevedo DE, Venturini GC, Azevedo AE, Marsico Pdos S. Video-assisted thoracoscopic removal of foreign bodies from the pleural cavity. J Bras Pneumol 2008; 34: 241-4. [CrossRef]

9. Dinka T, Kovács $\mathrm{O}$, Kotsis L. Emergency video-assisted thoracoscopic surgery for intrathoracic foreign bodies. Magy Seb 2004; 57: 346-50.

10. Akdur O, Özdemir Ç,Özkan S, İkizceli İ, Avşaroğulları L,Yıldırım T ve ark. Kurusıkı Kovan Patlamasına Bağlı Akciğer Kontüzyonu: Olgu Sunumu. Akademik Acil Tıp Dergisi 2009;OnlineBaskı. [CrossRef]

11. Kurnaz M, Çobanoğlu U, Yalçınkaya İ. Eşzamanlı Bilateral Torakotomi Uygulanan İki Hemotoraks Olgusu. Van Tıp Dergisi 2004; 11: 102-4.

12. Espada R, Whisennad HH, Mattox KL, Beall AC Jr. Surgical management of penetrating injuries to the coronary arteries. Surgery $1975 ; 78: 755-60$. [CrossRef]

13. Selinger L, Werner K, Silber R, Nellesen U, Inselmann G. Natural history of a ventriculoatrial fistula after a gunshot injury in 1945. Ann Thorac Surg 1998; 65: 1137-8. [CrossRef]

14. Oyar O, Yavuz MS, Köroğlu M. Vücut içerisine kalmış ve zamanla değişime uğramış bir mermi çekirdeği. Adli Bilimler Dergisi 2004; 3: 41-5.

15. Henkelman RM. Image artifacts, in Magnetic Resonance Imaging. Stark DD, Bradley WG. Eds.Mosby Year Book. St Louis: 1992. p.245. [CrossRef] 